\title{
El ñame espino (Dioscorea rotundata Poir.): una opción en la producción de jarabes edulcorantes intermedios para la industria alimentaria
}

\author{
Carlos Ramón Vidal Tovar \\ carlos.vidal@unad.edu.co \\ Universidad Nacional Abierta y a Distancia (UNAD) \\ Escuela de Ciencias Básicas Tecnología e Ingeniería (ECBTI) \\ CEAD Valledupar, Colombia
}

Resumen.-El objetivo principal de este trabajo fue la producción de jarabes intermedios por la hidrólisis enzimática aplicando la enzima $\alpha$-amilasa sobre soluciones al 36 y $46 \%$ de almidón de ñame (D. rotundata). La variable de respuesta fue el equivalente dextrosa en cada jarabe obtenido. Se utilizó un diseño completamente al azar. Los datos fueron analizados con el paquete estadístico Statgraphics ${ }^{\circledR}$. Los productos obtenidos fueron jarabes edulcorantes intermedios con un equivalente dextrosa de 18,81 y $22,15 \%$, respectivamente; luego de la licuefacción, -lo que permite clasificar como un jarabe de baja conversión por su bajo contenido de glucosa- los jarabes obtenidos pueden ser utilizados por sus propiedades funcionales como jarabes intermedios o como materia prima para diferentes procesos de la industria agroalimentaria como por ejemplo la fermentación con levaduras o la obtención de jarabes ricos en glucosas aplicando la sacarificación. Lo anterior permite establecer una pauta para el aprovechamiento del ñame como materia prima no convencional en la obtención de productos a partir del almidón.

Palabras clave: Almidón, Equivalente Dextrosa, Enzimas, Hidrólisis

\begin{abstract}
The principal objective of this study was the production of intermediate syrups by enzymatic hydrolysis using the enzyme $\alpha$-amylase on solutions of 36 and $46 \%$ (D. rotundata) The response variable was the dextrose equivalent in each syrup obtained. A completely randomized design was used. The data was analyzed using Statgraphics ${ }^{\circledR}$ statistical package. The products obtained were intermediate sweeteners syrups with a dextrose equivalent of 18.81 and $22.15 \%$, respectively; after liquefaction, -which allows classification as a low conversion syrup because of its low content of glucose syrups- the syrups obtained can be used for their functional properties as intermediate syrups or as raw material for various food industry processes such as fermentation by yeast or obtaining syrups rich in glucose by saccharification. This allows establishing a guideline for the use of yam as a non-conventional raw material in the production of products from starch.
\end{abstract}

Keywords: Starch, Dextrose Equivalent, Enzymes, Hydrolysis

\section{Introducción}

El ñame es una planta tropical de origen africano y asiático. Pertenece al orden Dioscoreales, familia Dioscoreáceas la cuál contiene 6 géneros pero Dioscorea es el más importante con 600 especies identificadas y sólo 12 especies son comestibles (Corpoica 2003).

En América, el ñame es importante en Brasil,
Colombia, Haití, Venezuela y Antillas francesas. En Colombia se pueden encontrar varias especies de ñame como el name criollo (Dioscorea alata L.), ñame espino (D. rotundata Poir.), ñame papa (Dioscorea bulbífera L.), ñame azúcar (D. esculenta [Lour.] Burk.) y ñampin (Dioscorea trifida L.f.). Se consideran D. alata y D. rotundata las especies de mayor importancia tanto por área sembrada como por demanda 
del tubérculo. De la producción total de name en Colombia, se calcula que el $17,7 \%$ se destina al autoconsumo, el 4,2\% para semilla y el $78,1 \%$ se dirigen al mercado en fresco. No es frecuente el uso en alimentación animal y actualmente los procesos de transformación no se realizan a escala industrial (Corpoica 2003).

El ñame espino es el más cultivado en el caribe colombiano y se conoce en otros países como ñame blanco. El tubérculo es aproximadamente de forma cilíndrica, la piel es lisa y de color marrón, y la carne por lo general de color blanco $y$ firme. La función del tubérculo en su mayor parte (zona central) es la de almacenamiento de gránulos de almidón. Los gránulos de almidón son redondeados o elípticos y algunas especies de ñame (D. rotundata) los concentran más que otras especies (Gamero 2000).

El almidón es una mezcla de dos polisacáridos que al tratarse con agua caliente se divide en dos fracciones: la amilosa que es soluble y que forma alrededor del $20-30 \%$ (se conocen variedades de maíz que poseen un contenido de amilosa del 50-80\%). El otro polisacárido es la amilopectina, la cual es insoluble y constituye alrededor del 70-80\% aunque sus contenidos varian en función de la fuente de obtención del almidón y de las características propias del cultivo; la amilosa es el producto de la condensación de D-glucopiranosas por medio de enlaces glicosídicos $\alpha(1,4)$, que establece largas cadenas lineales. La amilopectina, se diferencia de la amilosa en que contiene ramificaciones en forma de árbol, unidas por enlaces $\alpha$-D- $(1,6)$, ubicadas cada 15-25 unidades lineales de glucosa (Badui 1993). Los almidones comerciales se obtienen de las semillas de cereales (trigo, arroz) papa, batata y tapioca (Fennema 1993), arracacha, ibias, ñame y cubios (Corpoica 2003).

El valor de Equivalente Dextrosa (ED), es utilizado como un indicador del grado de hidrólisis de un jarabe. El ED del almidón es cero y el de la dextrosa es 100 (Quaglia \& Gennaro 2003); se define como el porcentaje de azucares reduc- tores de un jarabe, calculado como dextrosa en base seca (Badui 1993); en consecuencia, el ED de un producto de hidrólisis es igual a su poder reductor como \% del poder reductor de la dextrosa pura (D-Glucosa), y por tanto, el ED está inversamente relacionado con el peso molecular medio (Fennema 1993).

La mayoría de los procesos industriales utilizan las enzimas para hidrolizar parcial o totalmente el almidón a dextrinas, maltodextrinas y jarabes de glucosa o fructuosa por medio del rompimiento de las uniones $\alpha(1-4)$ y a (1-6). Esto también depende de la disponibilidad del almidón en la materia prima y el contenido de amilosa y amilopectina.

En el proceso de hidrólisis enzimática del almidón generalmente se pueden encontrar tres etapas básicas gelatinización, licuefacción y sacarificación. En el primer paso, el almidón es gelatinizado por un tratamiento térmico a temperaturas cercanas a $110^{\circ} \mathrm{C}, \mathrm{pH} 6,5 \mathrm{y}$ agua en exceso; durante el tratamiento térmico, el almidón es también hidrolizado por una $\alpha$-amilasa termoestable, la cual es adicionada a la solución de almidón al iniciar el tratamiento térmico; debido a las diferencias en la escala de tiempo de la gelatinización y del proceso enzimático de la licuefacción, el almidón gelificado se reduce rápidamente la temperatura hasta $95^{\circ} \mathrm{C}$ y se mantiene en esta temperatura por un tiempo de 60-90 minutos para completar la licuefacción enzimática. Después de este paso, se obtiene un producto que se asemeja a las maltodextrinas (ED 9-14). Se reduce el contenido de agua aumentando la viscosidad de la mezcla de reacción y la temperatura de fusión. Los aumentos de la temperatura de fusión son a partir de $72^{\circ} \mathrm{C}$ con humedad de $60 \%$ a $109^{\circ} \mathrm{C}$ con humedad $40 \%$ y $120^{\circ} \mathrm{C}$ con humedad $30 \%$. Se utiliza exceso del agua para facilitar la gelatinización y asegurar la suficiente mezcla durante la reacción (Van der Maarel et al. 2002).

La etapa de la gelatinización y licuefacción del almidón se lleva a cabo por las enzimas amila- 
sas especificas del enlace $\alpha(1-4)$; fueron clasificadas por Khun en alfa y beta. Las alfa amilasas liberan productos de reacción que tienen el grupo - $\mathrm{OH}$ situado en el carbono $\mathrm{C}_{1}$ en configuración $\alpha$, mientras que en las $\beta$ se encuentran en configuración beta. Las $\alpha$-amilasas atacan el almidón al azar y nunca en los extremos, lo que permite clasificarlas también como endoenzimas. Las $\boldsymbol{\alpha}$-amilasas actúan de forma aleatoria sobre los enlaces $\alpha(1-4)$ de la amilosa y la amilopectina, capaz de romper las uniones glucosídicas adyacentes a ambos lados del enlace $\alpha$ (16) de la amilopectina sin atacar directamente este enlace. Este ataque sobre las regiones interiores del sustrato causa un rápido descenso en la viscosidad de los almidones hinchados, producción de dextrinas y un cambio en la coloración del complejo yodo-almidón. Se les conoce como enzimas licuantes. Las $\alpha$-amilasas comerciales pueden ser de origen bacteriano o fúngico, las de origen bacteriano son más termoestables que las fúngicas. Las fúngicas se utilizan para la obtención de productos que contienen elevadas proporciones en maltosas (Martínez 2005).

De la hidrólisis enzimática se pueden obtener diferentes productos que se comercializan con nombres característicos a cada empresa que lo produce. se pueden encontrar jarabes con bajos niveles de ED de 20 a 37; jarabes de conversión regular con un DE de 38 a 50; jarabes ricos en maltosa con un ED de 38 a 55; jarabes de alto ED que se caracteriza por un DE de 55 a 80; jarabes de concentración menor de fructuosa similar a la de alto ED, excepto porque la fructosa está presente en un 9\%; jarabes hidrolizados de mayor conversión, con un ED por encima de 80 y contenidos de dextrosa que alcanzan el 100\%. Los jarabes que pertenecen a la familia de la isoglucosa y contienen jarabes isomerizados ricos en fructosa, con contenidos de fructosa que varían entre 10 a 55\% (Tate \& Lile 2008). Teniendo en cuenta el grado de conversión logrado por los jarabes o glucosas líquidas obtenidas en la hidrólisis enzimática parcial o total del almidón se pueden clasificar como: baja conversión con ED entre 28 y 37; conversión media o estándar con ED de 42; alta conversión ED de 55 o superior (Díaz et al. 2003).

El objetivo principal de este trabajo fue la producción de jarabes intermedios por la hidrólisis enzimática del almidón de ñame (D. rotundata) por medio de la aplicación de la enzima $\alpha$-amilasa. Con esta publicación se busca mostrar que el ñamepuede ser utilizado en la industria agroalimentaria para el desarrollo de otros procesos y como una forma alternativa de su aprovechamiento como materia prima no convencional en este tipo de procesos.

\section{Materiales y métodos}

\section{Producción del almidón de ñame (D. rotun- data)}

Se utilizó $25 \mathrm{~kg}$ de ñame espino (D. rotundata) obtenido en diferentes puntos del mercado de Bazurto de Cartagena de Indias, Colombia. Se implementó el proceso desarrollado por Corpoica en la obtención del almidón del ñame (Corpoica 2003). Los rizomas de ñame se lavaron con abundante agua fresca, eliminando los restos de impurezas. Se cortaron en segmentos para reducir su tamaño, facilitar su manipulación y completo lavado. Cada uno de los segmentos se troceó, peló y lavó de forma inmediata.

Los trozos de ñame, descascarados y limpios, se rallaron manualmente con un rallador que tradicionalmente se utiliza para rallar queso o coco; a la pasta obtenida fue llevada a una proporción con agua 1:10. Después de mezclar por 5 minutos se dejó por 2 horas en reposo; al completar la sedimentación de la mezcla fibra y almidón, se descartó el 70\% del contenido de agua teniendo la precaución de no agitar el sedimento el cual es una mezcla de agua, fibra y almidón; esta mezcla se sometió a un doble tamizado con coladores de uso común y tela tipo paño, respectivamente.

La mezcla lechada de almidón se le adicionó agua en proporción de 1:10, se mezcló por 5 
minutos y se sometió a sedimentación por una hora. Se retiró la máxima cantidad de agua teniendo el cuidado de no dejar escapar la parte con almidón. La lechada obtenida, se repartió en bandejas plástica y se sometió a secado a $45^{\circ} \mathrm{C}$ mezclando hasta alcanzar un $10 \%$ de humedad en un tiempo de 12 horas. El almidón obtenido se dejó a temperatura ambiente cubierto con un paño por 6 horas, se empacó en bolsas de polietileno de sello hermético para su posterior almacenamiento.

El diagrama de flujo del proceso aplicado se muestra en la Fig. 1

\section{Proceso de hidrólisis del almidón}

La enzima utilizada fue liquozyme supra, de la marca comercial Novozymes ${ }^{\circledR}$ y suminis-

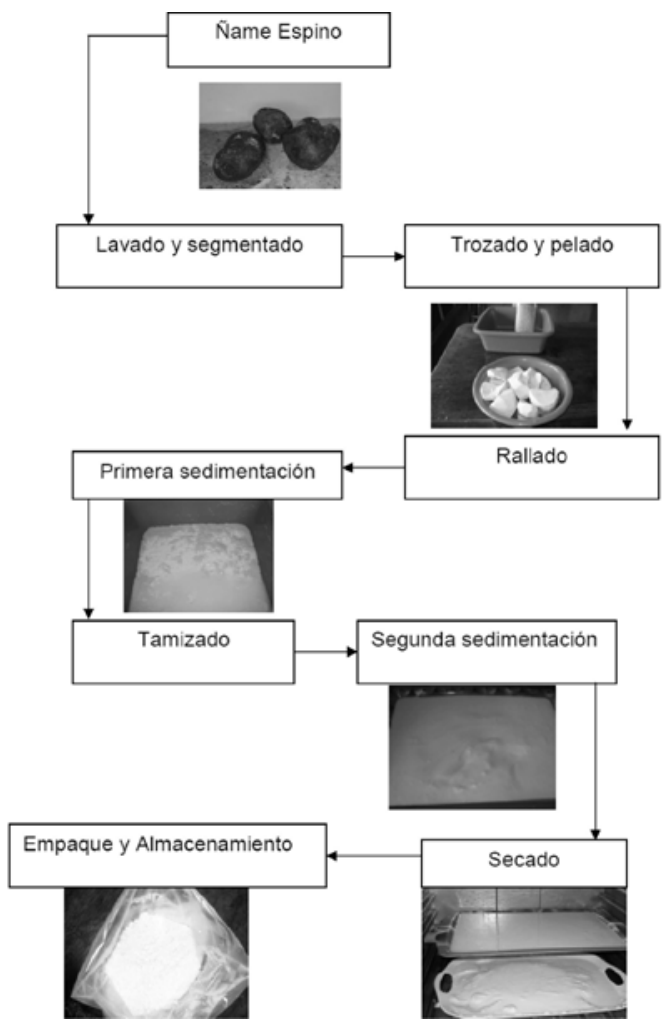

Figura 1. Diagrama de proceso aplicado para obtener el almidón de ñame. trada por la empresa Coldanzimas de Bogotá, Colombia. Liquozyme supra, es una alfa amilasa diseñada para desarrollar la primera y segunda licuefacción, puede ser adicionada directamente a la solución de almidón luego de ajustar el $\mathrm{pH}$ entre 5,2-5,6 a temperaturas entre $105-110^{\circ} \mathrm{C}$ para la primera licuefacción para un tiempo entre 5 a 10 minutos; en la segunda licuefacción a $95^{\circ} \mathrm{C}$ en un tiempo de 90 a 120 minutos, la dosificación empleada fue $0,52 \mathrm{~kg} \mathrm{t}^{-1}$ de peso seco de almidón; dependiendo del proceso donde se aplique, se puede inactivar bajando el $\mathrm{pH}$ a 3,8 y la temperatura a $90^{\circ} \mathrm{C}$ (Novozymes 2008).

El proceso de hidrólisis del almidón de ñame consistió en la aplicación de la enzima Liquozyme a soluciones al 36 y $46 \%$ de concentración

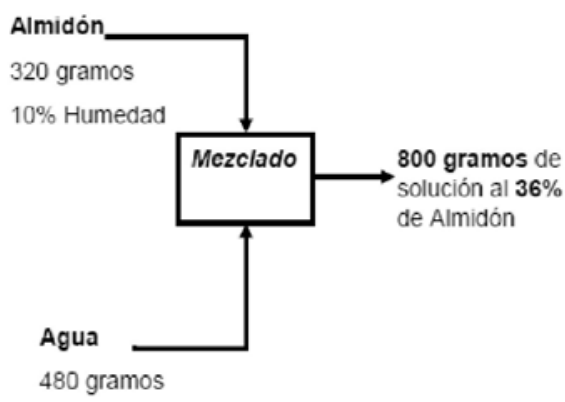

Figura 2. Balance de componentes de la solución de almidón al 36\% utilizada en los procesos de hidrólisis enzimática.

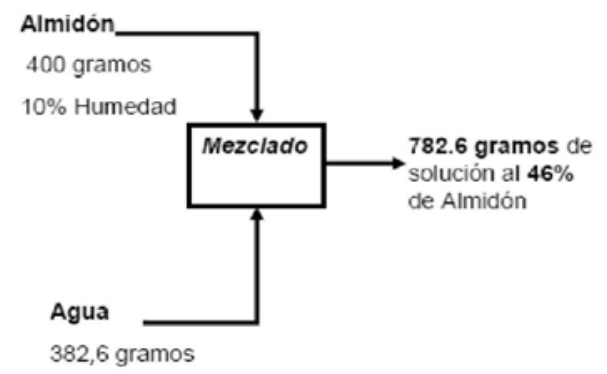

Figura 3. Balance de componentes de la solución de almidón al 46\% utilizada en los procesos de hidrólisis enzimática. 
de almidón. Muestran los balances de componente para preparar estas soluciones.

Se tomó cada una de las cantidades calculadas de almidón y agua en un matraz erlenmeyer de $1 \mathrm{~L}$ y se agitó hasta lograr la mezcla y total dilución del almidón; se ajustó el pH a 5,4 con una solución de ácido clorhídrico al $37 \%$, se adicionó $0,052 \%$ de enzima liquozyme teniendo en cuenta el peso seco de almidón utilizada en las soluciones de 36 y $46 \%$ de almidón. Se le colocó un tapón de caucho con un termómetro para controlar la temperatura de proceso.

La mezcla obtenida -almidón diluido más liquozyme- se sometió a un calentamiento progresivo con agitación constante en una estufa de agitación magnética Termolyne ${ }^{\circledR}$ hasta alcanzar $105^{\circ} \mathrm{C}$ por 5 minutos; luego, se disminuyó rápidamente la temperatura hasta $95^{\circ} \mathrm{C}$ en un baño de agua a temperatura ambiente, se mantuvo a esta temperatura en la estufa con agitación constante por 1 hora hasta alcanzar la licuefacción completa, la cual se determinó por el cambio paulatino de estado pastoso a líquido. La enzima se inactivó bajando la temperatura a $80^{\circ} \mathrm{C}$ por 5 minutos.

Para cada concentración de almidón se realizó la hidrólisis por triplicado. Se tomó $30 \mathrm{~g}$ de muestra de cada repetición y se analizó por triplicado. Los parámetros analizados fueron de azucares totales, azucares reductores, equivalente dextrosa, grados Brix, $\mathrm{pH}$ y humedad. Esta investigación se desarrolló en los Laboratorios de Análisis de Alimentos de la Universidad de Cartagena en la ciudad de Cartagena de Indias en Colombia.

\section{Métodos de Análisis}

\section{Almidón}

Para determinar la concentración de almidón en el almidón de ñame extraído, se aplicó el método utilizado por Martínez (2005); se tomó alícuotas de 2,$5 ; 5,0 ; 10,0$ y $20,0 \mathrm{~mL}$ y se completaron con agua destilada en balones aforados de
$25 \mathrm{~mL}$; se adicionó $0,5 \mathrm{~mL}$ de solución tampón fosfato y $0,5 \mathrm{~mL}$ de solución $0,2 \% \mathrm{I}_{2}$ y $2 \% \mathrm{KI}$. Además, se preparó un blanco con las mismas características. Para preparar la muestra de almidón de ñame, se pesaron $100 \mathrm{mg}$ de almidón de ñame y se completó con agua destilada en un balón aforado de $100 \mathrm{~mL}$; de esta solución se tomó $2 \mathrm{~mL}$ a un balón aforado de $25 \mathrm{~mL}$, se le adicionó $0,5 \mathrm{~mL}$ de solución tampón fosfato $\mathrm{y}$ $0,5 \mathrm{~mL}$ de solución $0,2 \% \mathrm{I}_{2}$ y $2 \%$ KI y se completó el volumen con agua destilada. La absorbancia se midió a $575 \mathrm{~nm}$ en el espectrofotómetro Uv-Vis Shimadzu Uv-1700 n (Martínez 2005).

\section{Amilosa/Amilopectina}

Para determinar el contenido de amilosa se utilizó el método colorimétrico de McGrance y Col, 1998 utilizando dimetilsulfóxido (DMSO) y aplicado por Martínez (2005), utilizando una recta patrón de amilosa preestablecida. El método consiste en tomar $0,1 \mathrm{~g}$ de muestra y adicionó en un tubo de ensayo $2 \mathrm{~mL}$ de DMSO; se disuelve por 15 minutos en un baño termostizado a $85^{\circ} \mathrm{C}$; luego se diluye con agua destilada hasta completar el volumen de un matraz aforado de $25 \mathrm{~mL}$; se tomó $1 \mathrm{~mL}$ de esta disolución y sobre él se añaden $5 \mathrm{~mL}$ de la solución de yodo y se completa el volumen a $50 \mathrm{~mL}$ y se mide la absorbancia a $600 \mathrm{~nm}$; con la absorbancia medida se determina en la curva patrón el contenido de amilosa en porcentaje, luego por diferencia se determina el contenido de amilopectina (Martínez 2005).

\section{Determinación de Azucares Reductores (AR), Azucares Totales (AT) y Equivalente Dextrosa (ED)}

Para la cuantificación de los azucares se utilizó el método volumétrico o iodométrico de Lane Eynon modificado y adaptado del método de la AOAC 923,09 (Horwitz \& Latimer 2005).

Para los cálculos se aplicaron las siguientes fórmulas:

$\mathrm{f}=($ volumen de solución gastados $)(\%$ solución de glucosa)(volumen de solución Fehling)/1.000 
donde,

f: título de la solución de Fehling

$\% \mathrm{AR}=\mathrm{f}$ (vol. solución de Fehling) $(10.000) /(\mathrm{VG})(\mathrm{VT})(2)$

$\% \mathrm{AT}=\mathrm{f}$ (vol. solución de Fehling)(10.000)/(VG)(VT) (3)

donde,

$\% A R$, porcentaje de azúcares reductores

$\% A T$, porcentaje de azúcares totales

VG, volumen gastado de solución de jarabe

$\mathrm{VT}$, volumen inicial tomado del jarabe

La cuantificación de ED se realizó tomando como base los azúcares reductores y la cantidad en sustancia seca de la muestra de jarabe utilizada, así:

$\% \mathrm{ED}=(\% \mathrm{AR} / \% \mathrm{SS})(100)$

donde,

$\% \mathrm{SS} \rightarrow$ porcentaje de sustancia seca $\rightarrow 100$ \%humedad de la muestra de jarabe

\section{Otras determinaciones}

Cenizas: se determinó por incineración directa, utilizando el método AOAC 981.12E, G(3) (AOAC1990).

Contenido de fibra cruda: el método utilizado fue el AOAC 962.09 (AOAC 1990).

Cuantificación de proteína: se utilizó el método de Biuret (Hung 1984) realizando una curva estándar de calibración de Albúmina Sérica Bovina (BSA) con concentraciones de 0,5; 1,$0 ; 1,5$ y $2,0 \mathrm{mg} \mathrm{L}^{-1}$.

Determinación de grasas: se determinó por el método de Soxhlet con sistema tecator AOAC 31.4.02 (AOAC 2005).

Determinación de pH: el pH de cada una de las muestras obtenidas en la aplicación de cada enzima fue medido mediante lectura directa con un pH-metro Metter Toledo Seven Easy ${ }^{\mathrm{TM}}$, teniendo en cuenta lo exigido en las normas NTC 4592 (ICONTEC 2004) y según el método AOAC 981.12 (Horwitz \& Latimer 2005).

Determinación de grados Brix: por refractometría, utilizando un refractómetro tipo Abbe con escala graduada en índice de refracción ( $1.300-1.700$ con apreciación 0,001 y en grados Brix de 0-100 con apreciación en $0,5^{\circ} \mathrm{Brix}$ ) norma NTC 4624 (ICONTEC 2004) y según método AOAC 932.14 (Horwitz \& Latimer 2005).
Determinación de la humedad: se determinó tomando aproximadamente $3 \mathrm{~g}$ de muestra aplicando una temperatura de $105^{\circ} \mathrm{C}$, modificando el tiempo de secado a 8 horas en una estufa marca Milton Roy Company, una balanza Metter Toledo SevenEasy ${ }^{\mathrm{TM}}$ y una campana desecadora norma NTC 572 (ICONTEC 2004) y método AOAC 925.10 (Horwitz \& Latimer 2005).

\section{Diseño estadístico experimental}

El diseño experimental utilizado es completamente al azar para probar el efecto de dos concentraciones de almidón de ñame sobre el proceso de hidrólisis enzimática parcial con la $\alpha$-amilasa liquozyme cuantificando como variable respuesta el equivalente dextrosa del jarabe obtenido. Los datos obtenidos fueron analizados con el paquete estadístico Statgraphics ${ }^{\circledR}$.

\section{Resultados}

\section{Obtención y caracterización del almidón de name}

El procesamiento de los $25 \mathrm{~kg}$ de ñame espino (D. rotundata) produjo los siguientes resultados:

- Cáscara y partes indeseables 3.652,00 g

- Name descascarado y acondicionado para el rayado $21.348,00 \mathrm{~g}$

- Ripios o residuos de tubérculos que no se permitieron rallar 597,74 g

- Pasta rallada compuesta por fibra y almidón 20.750,20 g

- Fibra descartada en la primera sedimentación: $1.667,35 \mathrm{~g}$

- Almidón con $10 \%$ de humedad 5.710,00 g

Como se puede observar, la cáscara y partes indeseables del tubérculo para el proceso de extracción de almidón corresponde a un 14,60\%; los residuos o pedazos de ñame que no permitieron ser rallados por su tamaño pequeño y difícil manipulación 2,39\%; la mezcla pastosa 
compuesta de almidón y material fibroso tuvo un rendimiento del 83,00\%. El desecho fibroso descartado en la primera sedimentación corresponde al 6,67\% del peso inicial del tubérculo utilizado. Para el almidón, se logró un rendimiento del $22,84 \%$ teniendo en cuenta la materia prima inicial $(25 \mathrm{~kg})$ y un $27,51 \%$ sobre la pasta rallada. La Tabla 1 presenta los resultados obtenidos de la caracterización del almidón de ñame.

Tabla 1. Composición del almidón de ñame obtenido.

\begin{tabular}{ll}
\hline Análisis & Concentración en \% \\
\hline Humedad & $10 \pm 0,39$ \\
Proteína & $1,43 \pm 0,005$ \\
Grasa & $0,046 \pm 0,0001$ \\
Ceniza & $0,165 \pm 0,005$ \\
Almidón & $79,64 \pm 0,12$ \\
Fibra & $0,7 \pm 0,05$ \\
Amilosa & $40,75 \pm 1,01$ \\
Amilopectina & $59,24 \pm 1,01$ \\
\hline
\end{tabular}

\section{Licuefacción del almidón de ñame por medio de la aplicación de la enzima liquozyme}

Los resultados obtenidos de azúcares reductores, azúcares totales, equivalente dextrosa, sólidos $\mathrm{y}^{\circ}$ Brix durante la aplicación de la enzima liquozyme se muestran en la Tabla 2. Se observó una producción de los azúcares reductores desde un 6,87 hasta $10,54 \%$; los azucares totales de 8,64 a $11,20 \%$; se logró un equivalente dextrosa entre $18,82 \mathrm{a} 22,15 \%$; los sólidos aumentaron del 35 a $45 \%$ y $l o{ }^{\circ}$ Brix de 34,0 a 42,6. El pH luego de la licuefacción del almidón estuvo entre 5,23 y 5,25 unidades. En la Fig. 4 se puede observar los resultados para azucares reductores, azucares totales y equivalente dextrosa en el proceso de hidrólisis utilizando las dos concentraciones de almidón de ñame utilizado.

\section{Hidrólisis del almidón de ñame}

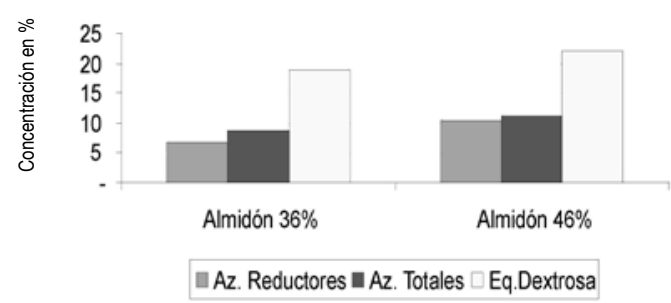

Figura 4. Resultados de la hidrólisis enzimática con liquozyme en soluciones de almidón al 36\% y 46\%. Az., azúcares; Eq., equivalente.

La Tabla 3 muestra las diferencias estadísticos de equivalente dextrosa para cada uno de los 2 niveles de \% de almidón. Se puede observar, que cuando se utiliza una concentración del $36 \%$ se obtiene $18,81 \pm 0,83 \%$ de ED y para una concentración de $46 \%$ de almidón se obtiene $22,15 \pm 2,77$.

Tabla 3. Resumen estadístico para equivalente dextrosa de la licuefacción del almidón de ñame.

\begin{tabular}{lllll}
\hline $\begin{array}{l}\text { \% de } \\
\text { Almidón }\end{array}$ & Media & $\begin{array}{l}\text { Media- } \\
\text { na }\end{array}$ & $\begin{array}{l}\text { Desviación } \\
\text { típica }\end{array}$ & $\begin{array}{l}\text { Error } \\
\text { estándar }\end{array}$ \\
\hline 36 & 18,81 & 18,76 & 0,83 & 0,34 \\
46 & 22,15 & 22,85 & 2,77 & 1,13 \\
Total & 20,48 & 19,70 & 2,62 & 0,76 \\
\hline
\end{tabular}

En la Tabla 4 se puede ver que existe diferencia estadísticamente significativa entre las medias de los ED del nivel de $46 \%$ almidón al nivel del $36 \%$ con $P \leq 0,05$.

Tabla 2. Caracterización de los jarabes obtenidos de cada proceso de hidrólisis aplicado al almidón de ñame.

\begin{tabular}{cccccc}
\hline Almidón & \%Az. Red. & \%Az. Tot. & ED & \%Sólidos & ${ }^{\circ}$ Brix \\
\hline $36 \%$ & $6,87 \pm 0,28$ & $8,64 \pm 0,27$ & $18,82 \pm 0,83$ & $36,50 \pm 0,31$ & $34,47 \pm 0,12$ \\
$46 \%$ & $10,54 \pm 1,33$ & $11,20 \pm 0,56$ & $22,15 \pm 2,77$ & $47,56 \pm 0,72$ & $42,6 \pm 0,20$ \\
\hline
\end{tabular}

\%Az. Red., porcentaje de azúcares reductores; \%Az. Tot., porcentaje de azúcares totales; ED, equivalente dextrosa. 
Tabla 4. Análisis de la varianza para equivalente dextrosa según el \%Almidón utilizado en la licuefacción.

\begin{tabular}{llllll}
\hline Fuente & Suma de cuadrados & Grados de libertad & Cuadrado Medio & Cociente-F & P-valor \\
\hline \%almidón & 33,53 & 1 & 33,53 & 8,01 & 0,0179 \\
Error & 41,87 & 10 & 4,19 & & \\
Total (Corr.) & 75,39 & 11 & & & \\
\hline
\end{tabular}

En la Tabla 5 se aprecia la diferencia estadística entre las medias de \%almidón. La mejor alternativa es $46 \%$. El método utilizado para discernir entre las medias es el procedimiento de las menores diferencias significativas de Fisher (LSD). Con este método, se logró un nivel de confianza $95,0 \%$ y un 5,0\% de riesgo de considerar cada par de medias como significativamente diferentes.

Tabla 5. Contraste múltiple de rango para equivalente dextrosa según \%almidón utilizado en la licuefacción.

\begin{tabular}{|c|c|c|c|}
\hline \multicolumn{4}{|c|}{ Método: $95,0 \%$ LSD } \\
\hline \%Almidón & Frec. & Media & Grupos homogéneos \\
\hline 36 & 6 & 18,81 & $\mathrm{X}$ \\
\hline 46 & 6 & 22,15 & $\mathrm{X}$ \\
\hline Contraste & \multicolumn{3}{|c|}{ Diferencias +/- Límites } \\
\hline $36-46$ & & *-3 & $34 \quad 2,63$ \\
\hline
\end{tabular}

* indica una diferencia significativa.

\section{Discusión y conclusiones}

Los valores obtenidos en rendimiento y composición del almidón de ñame son acordes con los señalados por Corpoica (2003) en Corpoica, Colombia; excepto el contenido de amilosa, el cual es mayor el encontrado en esta investigación $(40,75 \%)$ que el logrado por este autor $(31,1 \%)$ y Freitas (2004) (36\%). En otras variedades de ñame y para otros tubérculos y cereales evaluados por otros autores (Badui 1993, Corpoica 2003, Fennema 1993, Rivier 2001). El rendimiento obtenido en el procesamiento del ñame para la obtención de almidón y la composición del almidón son acordes a lo planteado por diferentes autores excepto en el contenido de amilosa que es superior al encontrado en otras investigaciones donde utilizan ñame u otros tubérculos, raíces o cereales.
Los rangos obtenidos de azúcares reductores, azúcares totales y ED se encuentran dentro de los señalados por diversos autores (Galindo 2000, Prochaska et al. 2007, Shariffa et al. 2009) utilizando almidón de plátano, yuca y papa, respectivamente.

El aumento de la concentración de almidón de 36 al 46\% produce un incremento de sólo 3,34 puntos en el ED del jarabe; esto puede ser debido a que el aumento de la concentración de almidón disminuye la actividad de la $\alpha$-amilasa (Baks et al.2006); se determinó que al utilizar una concentración del $46 \%$ se obtiene un valor medio ED mayor en un 3\% que cuando se utiliza una concentración del $36 \%$ de almidón; estos resultados permiten confirmar la actividad de la a-amilasa liquozyme sobre el almidón de ñame.

El equivalente dextrosa obtenido para las concentraciones de 36 y $46 \%$ de almidón utilizado puede ser debido al alto contenido de amilosa encontrado en el almidón de ñame hidrolizado $(40,75 \%)$; teniendo en cuenta que para la hidrólisis enzimática del almidón de papa es 26,9\% de contenido de amilosa (Delgado et al. 2009) y el $27,0 \%$ para el maíz (Badui 1993) se producen en la etapa de la licuefacción valores ED entre 9 a $15 \%$ al utilizar concentraciones de almidón entre 20 a 35\% (Buchholz \& Seibel 2008, Van der Veen et al. 2006).

Los productos obtenidos, se pueden considerar como jarabes intermedios de diferente composición ricos en oligosacáridos de cadenas lineales cortas o maltodextrinas que pueden ser mas adelante, convertidos por enzimas específicas a otros productos como jarabes ricos en maltosa, jarabes de alto contenido de azucares fermentables; jarabes utilizados en la industria para la 
fabricación de helados por el aporte de sus propiedades físicas que por su poder edulcorante; jarabes de gran interés por sus propiedades funcionales como la capacidad de formar geles, pastas y la estabilización de emulsiones agua/ aceite (Clarke 1993, Wojciech et al. 2003).

El incremento en la concentración de maltodextrinas en el proceso de licuefacción disminuye la actividad enzimática de las $\boldsymbol{\alpha}$-amilasas, las maltodextrinas pueden ser hidrolizadas por la $\alpha$-amilasa y compiten por sustrato (Baks et al. 2006).

El cambio de concentración de almidón utilizado en la hidrólisis de 36 al 46\% sólo representa un aumento ED 3,34\%, por la reducción del contenido de agua en la hidrólisis aumentando la viscosidad y exigiendo mejores condiciones de proceso u otro tipo.

Se encontró una diferencia estadística por la concentración de almidón utilizada en el proceso de hidrólisis en el ED del jarabe $(P \leq 0,05)$. El jarabe con mayor ED se produce al utilizar una concentración de almidón de ñame del $46 \%$.

El almidón extraído del ñame espino (D. rotundata), puede ser utilizado para obtener jarabes edulcorantes de aplicación en la industria alimentaria. La utilización de estos jarabes edulcorantes podría estar limitado por el uso común que tiene el azúcar o sacarosa como agente endulzante en los alimentos procesados.

\section{Agradecimientos}

A la Universidad Nacional Abierta y a Distancia UNAD y al SIUNAD por su apoyo incondicional en esta investigación.

\section{Literatura citada}

AOAC, Association of Official Analytical Chemists. 1990. Official methods of analysis of AOAC. 15th ed. Arlington.

Badui D., S. 1993. Química de alimentos. 3ra ed. Alhambra Mexicana, México.
Baks, T., A.E.M. Janssen \& R.M. Boom. 2006. The effect of carbohydrates on $\alpha$-amylase activity measurements. Enzyme and Microbial Technology, 39: 114-119.

Buchholz, K. \& J. Seibel. 2008. Industrial carbohydrate biotransformations, Carbohydrate Research, 343: 1966-1979.

Clarke, M.A. 1993. SYRUPS, Sugar Processing Research Institute Incorporated, New Orleans, LA, USA.

Corpoica. 2003. Concepción de un modelo de agroindustria rural para la elaboración de harina y almidón a partir de raíces y tubérculos promisorios, con énfasis en los casos de achira (Canna edulis), arracacha (Arracacia xanthorriza) y ñame (Dioscorea sp.) Informe Técnico Final. Corpoica; Pronata, Tibaitatá.

Delgado, R., A.J. Castro \& M. Vázquez. 2009. A kinetic assessment of the enzymatic hydrolysis of potato (Solanum tuberosum). LWT - Food Science and Technology, 42: 797-804.

Díaz G., A., L. Ricardo, B. Zaldivar \& G. Suárez. 2003. Análisis de la viscosidad de la glucosa cubana de la fábrica de hidrolizados de almidón de Cienfuegos. Tecnología Química, 23: 12-18.

Fennema, O.R. 1993. Química de los alimentos. Editorial Acribia, Zaragoza.

Galindo G., M.L. 2000. Optimización del proceso de obtención del almidón de sagú (Canna indi$c a)$, como estrategia sostenible en el desarrollo de actividades de agroindustria rural en diversas zonas de economía campesina colombianas. Tesis de grado. Bogotá: Universidad Antonio Nariño.

Gamero, V.G. 2000. Ecofisiología de cultivos, Consideraciones Sobre Fisiología de la Planta de Name. Disponible en línea. Turipana, http:// www.turipana.org.co/ecofisiologia_name.htm [Consultado en diciembre del 2008].

Horwitz, W. \& G. Latimer. (Eds.). 2005. Official methods of analysis of the AOAC. 18th ed. Association of Official Analytical Chemists (AOAC), Gaithersburg. 
Hung, N.D., Vas M., Cheke E. \& S.Z.A. Bolsci. 1984. Relatives trptic digestion rate of food proteins. Journal Food Science, 49: 1535-1542.

Instituto Colombiano de Normas Técnicas ICONTEC. . Norma técnica colombiana 572. Azucar. Determinacion de Humedad, Bogotá - Colombia, 2004.

Instituto Colombiano de Normas Técnicas ICONTEC. 2004. Norma técnica colombiana 1779. Miel De Caña. Método para Determinar Azucares Totales Expresados como Reductores, Bogotá.

Instituto Colombiano de Normas Técnicas ICONTEC. 2004. Norma técnica colombiana 4592. Productos de Frutas y Verduras. Determinación Del pH, Bogotá.

Instituto Colombiano de Normas Técnicas ICONTEC. 2004. Norma técnica colombiana 1779. Jugos De Frutas Y Hortalizas. Determinación Del Contenido de Sólidos Solubles. Método Refractométrico, Bogotá.

Krzyżaniak, W., W. Białas, A. Olesienkiewicz, T. Jankowski \& W. Grajek. 2003. Characteristics of oligosaccharides produced By enzymatic hydrolysis of potato starch using mixture of pullulanases and alpha-amylases. Disponible en linea. Electronic Journal of Polish Agricultural Universities, 6: http://www.ejpau.media.pl/volume6/issue2/food/art-16.html [Consultado en diciembre de 2010].

Martínez G., J.F. 2005. Utilización de [alfa]-amilasas en la formulación de detergentes industriales. Tesis de doctorado. Granada: Departamento de Ingeniería Química de la Universidad de Granada.
Novozymes. 2008. Fichas Liquozyme, Promozyme y Dextrozyme. Coldanzimas, Bogota.

Prochaska, K., P. Kędziora, J.L. Thanh \& G. Lewandowicz 2007. Surface properties of enzymatic hydrolysis products of octenylsuccinate starch derivatives. Food Hydrocolloids, 21: 654-659.

Quaglia, G.B. \& L. Gennaro. 2003. ENZYMES Uses in Food Processing. En: Macrae, R., R.K. Robinson, \& M.J. Sadler (Eds.). Encyclopedia of food sciences and nutrition. Academic Press, London. pp. 2125-2139.

Rivier, M., M.A. Moreno, F. Alarcón, R. Ruiz \& D. Dufour. 2001. Almidón agrio de yuca en Colombia. Tomo 2 Planta procesadora: descripción y planos de equipos. Publicación 323. Centro Internacional de Agricultura Tropical (CIAT), Cali.

Shariffa, Y.N., A.A. Karim, A. Fazilah \& I.S.M. Zaidul. 2009. Enzymatic hydrolysis of granular native and mildly heat-treated tapioca and sweet potato starches at sub-gelatinization temperature. Food Hydrocolloids, 23: 434-440.

Tate y Lile. 2008. Edulcorantes líquido. Amilungroup. Separata de productos.

Van der Maarel, M.J., B. Van der Veen, J.C. Uitdehaag, H. Leemhuis \& L. Dijkhuizen. 2002. Properties and applications of starch-converting enzymes of the alpha-amylase family. Journal of Biotechnology, 94: 137-55.

Van der Veen, M.E., S. Veelaert, A.J. Van der Goot \& R.M. Boom. 2006. Starch hydrolysis under low water conditions: a conceptual process design. Journal of Food Engineering, 75: 178-186.

Recibido: 30 de agosto de 2010 Aceptado: 13 de diciembre de 2010 